\title{
Social validity of a contextual behavioral science-based intervention for retirement education
}

\author{
Leonardo Martins Barbosa and Sheila Giardini Murta ${ }^{*}$ (D)
}

\begin{abstract}
The literature shows that retirement can bring both positive and negative effects. However, there are few tested interventions for preparing workers for this transition and avoiding or minimizing its negative impacts. This paper presents a study with multiple groups that examined the social validity of an intervention for retirement education grounded in contextual behavioral science and acceptance and commitment therapy. Twenty-seven workers aged 29 to 65 divided into three intervention groups participated (group 1, N=15; group 2, N=9; group 3, N=3). According to the participants' evaluations, the intervention provided socially valid goals, socially acceptable procedures, and socially important effects. However, some improvements are still needed, such as the use of more dynamic methods, better formatted printed material, and increased fidelity between the content's implementation and the prescribed activities. The positive results indicate that contextual behavioral science may bolster the development of interventions whose components possess evidence for their social validity. The further evaluation of the intervention via a clinical trial study will offer more robust evidence for its effectiveness. It is hoped that by increasing the availability of theory-based interventions in this area, the present study will promote valid strategies to facilitate better adjustment to retirement.
\end{abstract}

Keywords: Retirement, Aging, Social validity, Contextual behavioral science, Acceptance and commitment therapy

\section{Background}

How does retirement impact a worker's life? The answer is mixed: health can improve or worsen (van der Heide, van Rijn, Robroek, Burdorf, \& Proper, 2013), as can satisfaction with life (Bonsang \& Klein, 2012), marital life (Szinovacz \& Davey, 2005), closeness to children (Szinovacz \& Davey, 2001), leisure time (Nimrod, Janke, \& Kleiber, 2008), and amount of physical activity (Kämpfen \& Maurer, 2016), for example. Such variability stems from the personal and contextual resources available before and after retirement, which influence the impact of retirement and the worker's adjustment to it (Wang, Henkens, \& van Solinge, 2011). Thus, it is appropriate to invest in retirement preparation interventions that focus on maximizing the protective factors for adjustment to this phase of life.

\footnotetext{
* Correspondence: giardini@unb.br

Department of Clinical Psychology, University of Brasília, Brasília, DF CEP 70910-900, Brazil
}

Many of the factors which influence a worker's retired life are known, notably: physical health, finances, psychological factors, leisure, the voluntariness of retirement, and social interaction (Barbosa, Monteiro, \& Murta, 2016). However, few interventions have been developed and evaluated with the objective of modifying these factors (Boehs, Medina, Bardagi, Luna, \& Silva, 2017; Hurtado \& Topa, 2019; Pazzim \& Marin, 2017). A review by Leandro-França, Murta, Hershey, and Barbosa (2016) consulted 13 databases in search of retirement education studies written in Portuguese, Spanish, or English that included the description and evaluation of the procedures and results. Encompassing publications before 2015 , only 11 matched the inclusion criteria, all group interventions. Furthermore, many of the studies presented limitations in design, instrument quality, and/ or a lack of robust data analysis. The scarcity of properly developed and tested interventions reduces the worker's preparedness for retirement. In turn, this poor preparedness can increase the worker's vulnerability to 
adjustment problems and reduce quality of life. To minimize such risks, developing and evaluating retirement education interventions more rigorously is recommendable.

\section{Intervention development and social validity}

Intervention development is part of the research cycle of prevention and promotion in mental health (Murta \& Santos, 2015). The cycle may be divided into seven stages (Muñoz, Mrazek, \& Haggerty, 1996) related to the target problem: descriptive studies, to assess the problem prevalence and incidence; etiological studies, to identify the risk and protection factors for the problem in question; development studies, to construct and test the intervention's viability and acceptability; efficacy and effectiveness studies, to evaluate the intervention's effects; and diffusion and cultural adaptation studies, to transfer and adjust the intervention to other contexts and cultures. Intervention development is further divided into three substages (Rohrbach, 2014): theoretical foundation, which identifies the target-public, describes the problem and its theory-based determinants, and defines the objectives; program construction, which selects and integrates several techniques according to the context and the population's characteristics; and the pilot, which evaluates the effects of the intervention's individual activities and general outcomes. One of the expected products of this cycle is an intervention that participants evaluate as socially valid.

The social validity of an intervention encompasses the social significance of the goals, the social acceptability of the procedures, and the social importance of the intervention's effects (Fawcett, 1991; Wolf, 1978). This concept arose at the end of the 1960s as a distinctive characteristic of applied behavior analysis, which differed from experimental behavior analysis by emphasizing the social relevance of the studied problems (Baer \& Wolf, 1987). In the following years, the concept spread due to the increased community participation in interventions and currently it has at least 12 definitions (Carter, 2010).

Besides helping legitimize the results, social validity can also boost implementation quality (Lane \& BeebeFrankenberger, 2004), an aspect which deserves special attention. Durlak and DuPre's (2008) review identified 23 factors that can influence the implementation quality of health prevention and promotion programs, organized into five categories: community factors, such as policies for preventing mental health problems and promoting good mental health; provider's characteristics, such as the ability to implement the intervention; innovative characteristics, such as the possibility of adapting the intervention to the population; organizational capacity, such as institutional openness to change; and means of delivery, such as the training of the professionals who will conduct the intervention. Based on a sample of 542 studies, their results show that well-implemented interventions produce effects two- to threefold greater than less carefully implemented interventions. As the authors attest, implementation matters. However, none of the interventions reviewed by Leandro-França et al. (2016) include evaluations of social validity.

\section{A systematic approach for the development of interventions}

Six decades ago, Kurt Lewin remarked that "nothing is as practical as a good theory" (Lewin, 1951), p. 169. A good theory helps to identify the determinants of behavior and the process of change, besides guiding the choice of intervention techniques, maximizing the results, or pointing out necessary changes (Bartholomew \& Mullen, 2011). On the other hand, an implicit and inarticulate theoretical foundation muddles the understanding of the workings and adaptation of an intervention (Herbert, Gaudiano, \& Forman, 2013). Such problems may have compromised the consistency of the majority of retirement education interventions that are not explicitly theoretically based (Leandro-França et al., 2016): out of the 11 articles reviewed by the authors, only five mention the theories that guided the intervention developmentFRAMES model $(\mathrm{F}=$ feedback, $\mathrm{R}=$ responsibility, $\mathrm{A}=\mathrm{ad}-$ vice, $\mathrm{M}=$ menu of options, $\mathrm{E}=$ empathy, $\mathrm{S}=$ self-efficacy), transtheoretical change model, social cognitive theory, appropriate retirement decision model, and image theory. As such, retirement education studies may lack strong conceptual bases.

One proposal to overcome this issue is to guide the development of the various knowledge construction stages by common principles, emphasizing a natural cohesion among the different levels and dimensions of knowledge. Contextual behavioral science (CBS) (Vilardaga, Hayes, Levin, \& Muto, 2009) fits this objective. CBS is a science development strategy that integrates applied basic principles, theories, and models that attempt to predict and influence the actions of individuals and groups. Its research program includes philosophical assumptions, basic and applied theory, and intervention development. In essence, it consists of a systematic application of contextual thought to different levels and dimensions (Pepper, 1942).

CBS is based on functional contextualism, a pragmatic system characterized by four essential criteria (Biglan \& Hayes, 1996; Hayes, Hayes, \& Reese, 1988). The first is the prediction-and-influence of behavior: prediction and influence as a single objective in the sense that only analyses that include both are considered valid (Hayes et al., 1988). Second is the act-in-context as the basic unit of analysis: the necessity of considering an event in the historical and environmental situation in which it occurred. 
Third comes functionality as a criterion for truth; regardless of the considerations of a possible underlying structure of the world, the analyses useful for the previously established objectives are considered true. In an analysis, variables are sought that permit predicting an event's occurrence as well as influencing its likelihood in the groups where that event can be modified. In fourth place comes a unitary vision of the human being, understood as a unified organism. Thus, thoughts, feelings, and behaviors are considered actions on the same level, without hierarchy (Hayes \& Brownstein, 1986).

CBS extends its pragmatism to several theories, understood as systematic and comprehensive analysis of actsin-context with the purpose of predicting-andinfluencing the actions of individuals and groups (Hayes, Barnes-Holmes, \& Wilson, 2012). Relational Frame Theory (Hayes, Barnes-Holmes, \& Roche, 2001) is an example of a basic theory with practical applications. It is a theory of cognition and human language based on the learned ability to relate symbols arbitrarily. Understanding the function and context of those relationships may allow predicting and manipulating their subjective impact.

At the level of intervention development, acceptance and commitment therapy (ACT) is an example of approach based on the contextual principles (Barbosa \& Murta, 2014; Hayes, Strosahl, \& Wilson, 2012). ACT is a clinical model of health, psychopathology, and intervention that aims to promote psychological flexibility: the ability to maintain or change behavior, in a conscious and intentional manner, as a function of one's values (Hayes, Luoma, Bond, Masuda, \& Lillis, 2006). While the flexibility comes from the functional use of psychological mechanisms, the dysfunctional use of the same mechanisms can result in psychopathology. Finally, CBS is a comprehensive strategy for the promotion of science. It is based on fundamental principles which are subject to updating and it seeks to integrate areas of knowledge that share common principles, thereby improving the development of knowledge itself. Besides integrating different dimensions and levels of knowledge, CBS also indicates criteria to guide the scientific research agenda, as seen in various articles (Hayes, Long, Levin, \& Follette, 2013; Hayes, Strosahl, \& Wilson, 2012; Vilardaga et al., 2009). For example, a study by Hayes et al. (2013) suggests several ways to improve the intervention development process, such as coordinating research concerning interventions and philosophical assumptions; emphasizing functional processes, which must be manipulable; planning and disseminating the implementation after the initial stages; adopting models applicable to the public health care dimension; precocious effectiveness testing; and researching transdiagnostic comprehensiveness.
In short, retirement education intervention development seems two have two significant gaps: interventions that lack explicit theoretical foundation and a scarcity of resources. In this context, the construction and social validation of a retirement education intervention and the application of CBS as a guide for this process is a first step in closing both of these and complementing the current literature. Hence, the present article's objective is to describe the development and examine the social validity of a retirement preparation intervention based on CBS. Specifically, the study aims to examine the social significance of its goals, the social acceptability of its procedures, and the social importance of its effects.

\section{Method}

\section{Participants}

Given the intervention's stage of development, a multiple group study was done. Retirement education applied to three groups of workers transitioning to retirement from three different contexts in the city of Brasilia, Brazil, between August 2015 and December 2015 was analyzed. According to the original schedule, the groups' interventions were to be done sequentially so problems identified in one group could inform changes to the subsequent one(s). However, due to the institutions' availabilities, the schedule was changed and there was some overlap in the implementations.

Altogether, 27 workers aged 29 to $65(M=61)$ participated in the study ( 22 women and five men). Group 1 had 15 workers, 13 women and 2 men; group 2, nine, seven women and two men; and group 3 , three participants, two women and one man.

Group 1 took place in a federal institution which manages science policies; group 2, in an arm of the federal justice department; and group 3, with workers identified through a professional researchers' network. The only inclusion criterion was interest in participating in the intervention, regardless of age or the amount of time until or after retirement.

\section{Instruments}

Needs Assessment and Results Evaluation Questionnaire. This information was collected through open questions developed by this study's authors. At the beginning of the intervention, participants stated their needs and their expectations regarding the activity respectively by completing the sentences, "I sought out this activity because ..." and "By the end of this activity, I expect to...." To indicate the achieved results, at the end of the intervention, participants completed the sentence, "When I compare my expectations with my results, I think that ...."

Valued Living Questionnaire (VLQ) (Wilson, Sandoz, Kitchens, \& Roberts, 2010). The themes to be worked on 
each encounter were identified and selected using a version of the VLQ translated into Portuguese by the present study's authors. Through a 10-point Likert-type scale, the instrument assesses the personal relevance of ten life domains and how much the individual's behavior is oriented toward them.

ACT Matrix (Polk \& Schoendorff, 2014). This is a diagram based on the ACT model that undertakes to promote psychological flexibility. It helps the individual or the group to discriminate (1) mental/sensory stimuli from behaviors and (2) living congruently from living incongruently with one's own values. The matrix consists of the intersection of two perpendicular lines: a horizontal line that separates mental/sensory stimuli (lower half) from externally observable behaviors (upper half) and a vertical line that separates what is incongruent with values (left side) from what is congruent with values (right side). This cross-like diagram creates quadrants into which experiences are categorized: aversive internal events (lower left), dysfunctional actions (upper left), values (lower right), and goals (upper right). This categorization allows participants to identify their own themes (life domains) and values of interest as well as the behaviors they are willing to commit to.

Satisfaction Perception Scale. A scale developed by the present study's authors to assess satisfaction with the intervention. On a 10-point Likert-type scale, at the end of each meeting, the participants expressed their satisfaction with the facilitator, content, material, and the intervention in general. Additionally, they could describe the positive and negative aspects of each item.

Behavioral Activation Table (Kanter, Busch, \& Rusch, 2009). This instrument is used to promote the practice of new behaviors. The table comprises four columns in which the participant describes a behavior, the contingencies for its fulfillment, its potential obstacles, and the possible solutions for such obstacles.

Activity Monitoring Chart (Kanter et al., 2009). This instrument attempts to identify behavioral patterns and their frequencies. It consists of a table with two columns. The first lists ten life domains (for example, health or social life) and the second provides space for the participant to record the daily activities undertaken in each area.

\section{Procedures}

\section{Intervention}

The intervention will be described according to the Template for Intervention Description and Replication Checklist and Guide (TIDieR) (Hoffmann et al., 2014):

Brief name: The intervention was not named.

Why: The intervention was developed based on retirement education interventions described in the literature (Leandro-França et al., 2016; Murta et al., 2014). It is theoretically based on Contextual Behavior Science and on Acceptance and Commitment Therapy. CBS is a science development strategy focused on principles that promote integration between applied basic principles, theories, and models that attempt to predict and influence the actions of individuals and groups. Its research program includes philosophical assumptions, basic and applied theory, and intervention development. ACT is a clinical model of health, psychopathology, and intervention that aims to promote the ability to maintain or change behavior, in a conscious and intentional manner as a function of one's values.

What (materials): Printed materials were used, including a list of values and a list of retirement adjustment predictors. The list of values aggregates expressions obtained from the Survey of Guiding Principles (SGP) (Ciarrochi \& Bailey, 2008). The list presents expressions that participants can choose or adapt to identify their own values, such as connection with nature, honesty, helping others, loyalty, romantic relationships, practicing sports, and eating healthy. The list of predictors was based on an integrative literature review about retirement adjustment predictors (Barbosa et al., 2016). Only predictors with broad empirical bases and evidence for positive effect were presented and discussed: psychological and physical health, finances, leisure, voluntary retirement, social interaction, retirement preparedness, marital relationship, post-retirement work, work conditions before retirement, spirituality, retirement length, parenting, and education.

What (procedures): Table 1 summarizes activities developed in each meeting for the three groups. Procedures included informative activities, such as presentation of retirement adjustment predictors, and practical activities, such as discussions about the themes chosen by the participants, values, and averse internal events. The number of life domains addressed in each group, however, varied according to the number of meetings: in group 1, two domains of life were addressed; in group 2, three domains; and in group 3, five domains.

Who provided: The intervention was facilitated by the first author, who had 9 years of experience working as a clinical psychologist and 5 years as a group facilitator at the time of the study.

How: The intervention was delivered face-to-face in group format.

Where: Groups 1 and 2 met in institutions and group 3 , in a private office. The three settings were similar: a private room with individual desks, windows, airconditioning, and video projectors and screen.

When and how much: In group 1, four monthly 3-h meetings were conducted in an open group (accepting new participants throughout the meetings), totaling $12 \mathrm{~h}$. In group 2, five weekly 2 -h meetings were held in a 
Table 1 Content of the meetings

\begin{tabular}{|c|c|c|}
\hline Meeting & Activity & Group \\
\hline \multirow[t]{6}{*}{1} & Presentation of the intervention & $1,2,3$ \\
\hline & Predictors of adjustment to retirement & $1,2,3$ \\
\hline & Presentation of the ACT Matrix & $1,2,3$ \\
\hline & List of values & $1,2,3$ \\
\hline & Task: activity monitoring chart & $1,2,3$ \\
\hline & Meeting evaluation & $1,2,3$ \\
\hline \multirow[t]{6}{*}{2} & Results of previous meeting evaluation & $1,2,3$ \\
\hline & VLQ: three main life domains & $1,2,3$ \\
\hline & ACT Matrix: first life domain & $1,2,3$ \\
\hline & Task: behavioral activation table & $1,2,3$ \\
\hline & Task: describing first life domain relevance & $1,2,3$ \\
\hline & Meeting evaluation & $1,2,3$ \\
\hline \multirow[t]{6}{*}{3} & Results of previous meeting evaluation & $1,2,3$ \\
\hline & Task review & $1,2,3$ \\
\hline & ACT Matrix—second life domain & $1,2,3$ \\
\hline & Task: behavioral activation table & $1,2,3$ \\
\hline & Task: describing second life domain relevance & $1,2,3$ \\
\hline & Meeting evaluation & $1,2,3$ \\
\hline \multirow[t]{6}{*}{4} & Results of previous meeting evaluation & 2,3 \\
\hline & Task review & 2,3 \\
\hline & ACT Matrix - third life domain & 2,3 \\
\hline & Task: behavioral activation table & 2,3 \\
\hline & Task: describing third life domain relevance & 2,3 \\
\hline & Meeting evaluation & 2,3 \\
\hline \multirow[t]{6}{*}{5} & Results of previous meeting evaluation & 3 \\
\hline & Task review & 3 \\
\hline & ACT Matrix_fourth life domain & 3 \\
\hline & Task: behavioral activation table & 3 \\
\hline & Task: describing fourth life domain relevance & 3 \\
\hline & Meeting evaluation & 3 \\
\hline \multirow[t]{7}{*}{6} & Results of previous meeting evaluation & 3 \\
\hline & Task review & 3 \\
\hline & ACT Matrix_fifth life domain & 3 \\
\hline & Task: behavioral activation table & 3 \\
\hline & Task: describing fifth life domain relevance & 3 \\
\hline & Task: individual plans for retirement & 3 \\
\hline & Meeting evaluation & 3 \\
\hline \multirow[t]{4}{*}{7} & Results of previous meeting evaluation & $1,2,3$ \\
\hline & Task review & $1,2,3$ \\
\hline & Next steps & $1,2,3$ \\
\hline & Intervention evaluation & $1,2,3$ \\
\hline
\end{tabular}

closed group (new participants would not be admitted after the first meeting), totaling $10 \mathrm{~h}$. In group 3, seven 90-min weekly sessions were conducted in a closed group, totaling $10.5 \mathrm{~h}$.

Tailoring: The intervention focused on social validity and the authors expected to adapt it as much as possible according to participant feedback while in progress. To reach that goal, every meeting was concluded with an evaluation. The feedback was then evaluated by the authors, who implemented the changes in the following meeting. When this was not possible, changes affected the development of the following groups. Table 1 summarizes how changes were implemented throughout the groups.

Modifications: Initial design and dosage proposed closed groups, with four weekly sessions, each session lasting $3 \mathrm{~h}$, totaling $12 \mathrm{~h}$. However, in group 1, the institution coordinator requested the authors to allow new participants and offer monthly sessions. Both suggestions impacted the intervention negatively, so groups 2 and 3 were closed and had weekly sessions. In group 2, participants preferred to reduce each meeting duration (from $3 \mathrm{~h}$ to $2 \mathrm{~h}$ ) and to increase the number of meetings (from four to five). In group 3, the number of meetings was increased again because group 2 participants had said they would like to work additional life domains. In order to minimize impacts in dosage, meeting duration was reduced to $90 \mathrm{~min}$.

How well (planned): Intervention fidelity was not evaluated.

How well (actual): Intervention fidelity was not evaluated.

\section{Data collection}

Participants individually answered the Needs Assessment and Results Evaluation Questionnaire and Valued Living Questionnaire in the first meeting. The Activity Monitoring Chart was assigned in meeting 1 as homework to be answered daily by each participant until meeting 2 . The ACT Matrix was used in meetings 2 through 7, inclusive. Participants answered it collaboratively in group. The Behavioral Activation Table was answered individually each meeting after answering the ACT Matrix. The Satisfaction Perception Scale was applied at the end of each meeting and answered individually.

\section{Data analysis}

The data analysis considered the distinctiveness of each group, the variability of contexts and groups, and their relative contribution to understanding the evidence for social validity of the goals, procedures, and effects. Hence, each group was analyzed relative to one of the three social validity components. Textual data were analyzed separately by two judges according to the 
procedure suggested by Braun and Clarke (2006). First, the participants' answers were read over several times and then divided in basic units of analysis, each containing only one characteristic, positive or negative. Each unit was classified according to the theme and the themes were organized into more comprehensive categories. These categories were then compared to the original data and the discrepancies led to refinement of the final thematic categories. The quantitative data were tallied and analyzed by means of two descriptive statistics, frequency and mean.

In group 1, it was analyzed the social significance of the goals, based on the use of the ACT Matrix. This analysis was based on five criteria proposed by Lane and Beebe-Frankenberger (2004): the preferences and values of the consumer, the promotion of common skills between peers that are relevant in different contexts, the option to choose goals of personal interest, and the option to take advantage of pre-existing skills or to adapt aspects of the treatment. The participants' reports were organized accordingly, indicating whether a given criterion had been met. In group 2, it was analyzed the social acceptability of procedures through reports and satisfaction scores. The satisfaction reports obtained for each item (facilitator, material, content, and general) were interpreted by identifying the aforementioned themes and their frequency. The satisfaction scores obtained for each item were grouped by meeting and presented as mean values for each category. In group 3, it was analyzed the social importance of the effects via the commitment to their goals and the final evaluation of the results. The commitment was evaluated through a weekly review of the goals, comparing a participant's performance to the goal established in the prior meeting. The final evaluation of the results was analyzed in contrast with the reported initial expectations, revealing whether the intervention met the expectations.

\section{Results}

\section{Group 1}

Group 1 was the first intervention implementation and it remained open to new participants. A total of 15 individuals participated, with around nine present at each meeting. Data from this group was used to analyze the social significance of the themes. To this end, the results of two activities done in the third meeting will be presented: the task review and the filling in of the matrix. Figure 1 present the matrix filled in meetings 2 and 3 regarding the theme of health.

Figure 2 presents the matrix as filled out in meeting 3. This time, the participants chose different life areas: career, education, citizenship, and spirituality. The

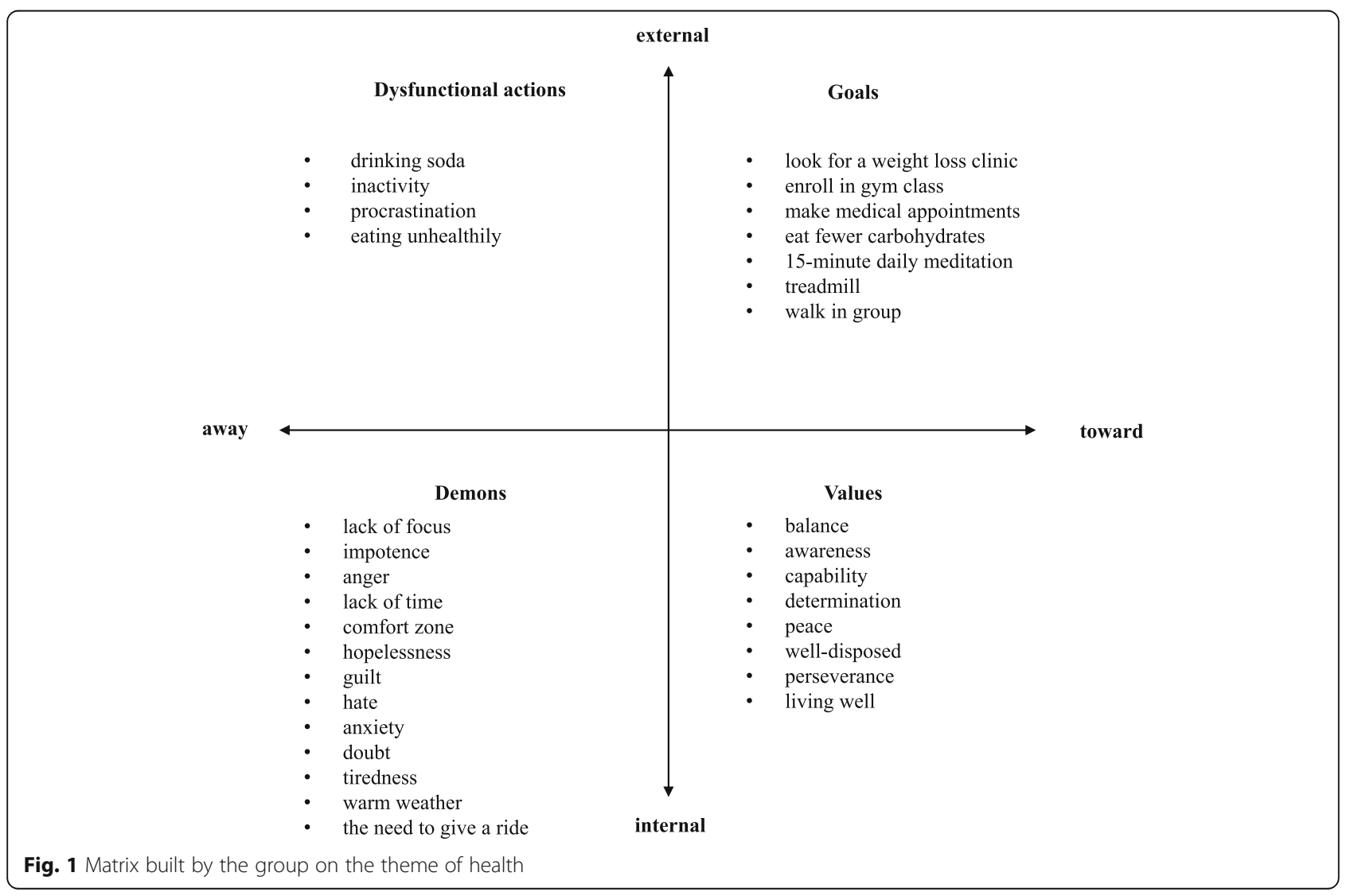




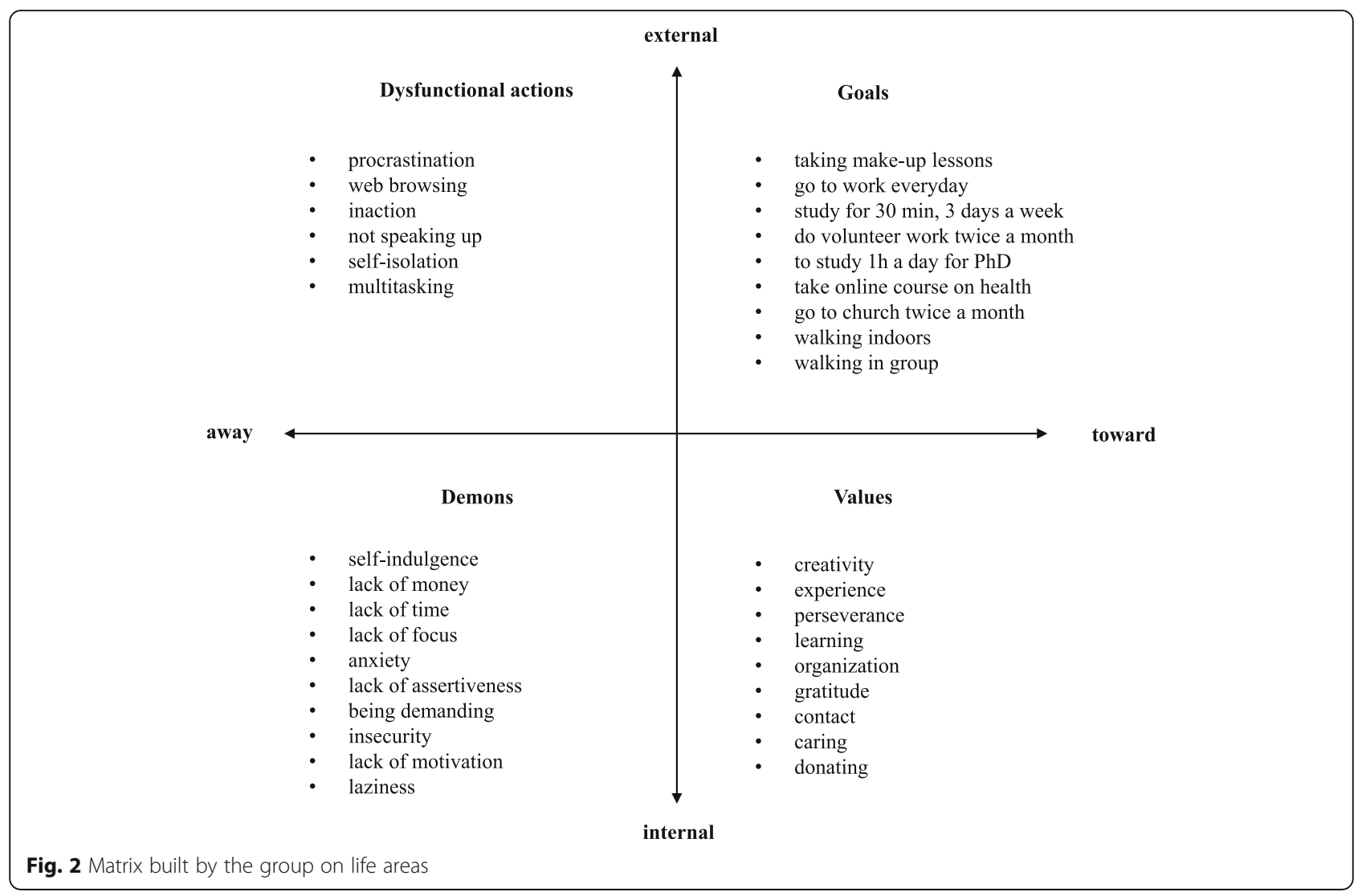

possibility of addressing different areas concomitantly reveals two important characteristics of the instrument employed. On the on hand, it allows individualization of one's own retirement preparation-values, obstacles, and goals according to personal interests. On the other, it promotes collaboration among the participants who share objectives and difficulties even when working on different themes.

In goal definition, the participants also worked together: for example, the task of "walking in a closed environment" was agreed upon by four participants who planned to do the activity together at lunchtime in the institution's courtyard. The "walking in group" activity was agreed to by two participants who live near each other and planned to exercise before work.

\section{Group 2}

Group 2 was the second implementation of the intervention. Based on the experience with the previous group, this group was closed. Two of the nine participants dropped out over the course of the meetings. At the request of the agency's human resources coordinator, the intervention was increased to five meetings.

Data from this group was used to analyze the social acceptability of the procedures. To this end, the results of the qualitative and quantitative satisfaction evaluations done at the end of the meetings will be presented. Table 1 shows the positive and negative aspect categories reported by the participants, as well as the average satisfaction with each intervention item.

There were 37 positive comments about the facilitator, classified into four categories: assertiveness $(n=13$, e.g., "objective"), flexibility ( $n=13$, e.g., "willing to listen"), attentive to the present $(n=8$, e.g., "connected with the group"), and satisfying ( $n=3$, e.g., "I liked it"). There were eight negative comments, classified into three categories: conduct ( $n=4$, e.g., "I'm finding the pace fast"), time ( $n=2$, e.g., "too little time"), and clarity $(n=2$, e.g., "sometimes I don't understand where the activity is going").

There were 19 positive comments regarding the content and procedures that were classified into four categories: productive $(n=8$, e.g., "allowed for introspection"), clarity ( $n=6$, e.g., "enhanced the program's objective"), satisfaction ( $n=3$, e.g., "appropriate"), welltailored ( $n=2$; “focused on the group's rhythm").

On the negative side, there were nine comments grouped into three categories: poor instruction $(n=4$, e.g., "have more practical examples"), lack of time ( $n=4$; "was hampered by too little time"), and low social interaction $(n=1$; "absent coworkers could have added a lot"). 
The material garnered 19 positive comments classified into three categories: satisfaction $(n=10$, e.g., "I liked it"), instruction ( $n=7$, e.g., "instructive"), and responsiveness ( $n=2$; "my previous complaint was addressed"). There were seven negative comments, which were grouped into two categories: improving the material ( $n=5$, e.g., "the lack of numbering hinders using the material during the meeting") and incompleteness $(n=2$, e.g., "I wanted to see more than what the facilitator brought").

As for the general evaluation, there were 17 positive comments classified into three categories: satisfaction ( $n=7$, e.g., "very good"), personally beneficial $(n=4$; "I was happy for having listed suggestions and responded"), and social interaction $(n=2$; "great group work"). On the other side, there were nine negative comments grouped into three categories: lack of social interaction $(n=3$, e.g., "lots of people absent"), general procedures ( $n=3$, e.g., "balance the lecture part"), and personal problems $(n=3$, e.g., "at this point in my life, I'm focused on my ghosts.").

In total, there were 121 comments, 88 positive and 33 negative. The matrix was another important element. Although it was not cited in the comments, adhesion on the part of the participants qualified both to identifying values, objectives, and obstacles and planning changes.

Three other procedures also had undesired consequences. First, in group 1, the intervention was open to new participants after the first meeting. As such, it was necessary to re-present it several times, which undermined group consolidation and the continuity of work. To avoid this problem, new participants were not allowed to join the following interventions after the first meeting. Second, in groups 1 and 2, the intervention happened at the participants' workplace and professional demands hampered their adherence. On the other hand, offering the intervention in the institution itself made it more accessible to the participants. Third, in group 2, the institution's coordinator announced the intervention only to colleagues who had participated in other life quality programs, including a long-term retirement preparation intervention.

\section{Group 3}

Group 3 was the last implementation and had three participants selected by convenience. To promote the addressing of more life areas, two additionally meetings were added, making a total of seven. To avoid large difference in workload, the meeting duration was reduced to $1.5 \mathrm{~h}$. Thus, while group 2 had a workload of $10 \mathrm{~h}$, with five 2-h meetings, the workload of group 3 was $10.5 \mathrm{~h}$ from seven 1.5 -h meetings.

Data from this group was used to evaluate the social importance of the effects. For this, the behavioral effects resulting from the meetings will be presented. Table 2 shows the individual routines in the first week of the intervention. It can be seen that physical exercise is quite common, with a large variety of activities. Although participant 1 is retired from a career in medicine, she regularly undertakes activities in her post-retirement career as a teacher. Observe as well as participant 3 did not take part in activities with friends and that all her leisure activities are solitary ones. Table 2 covers only the areas all participants worked in the intervention; so the fields of "friendship" (participants 1 and 2) and "intimate relationship" (participant 3) were not considered. In Table 3, only activities related to the life areas worked during the intervention are presented.

Tables 4, 5, and 6 present individual data on the expectations, new behaviors, and the evaluation of intervention effects. The expectations section contains the motive for and expectations of participating in the intervention, which were collected at the beginning of the first meeting. The goals section lists each meeting's theme and the monitoring of respective goals, done starting from the second week. The final evaluation section, answered in the last meeting, has the participants' evaluations of the intervention's effects.

Table 4 shows that, with the exception of daily meditation, all the goals of participant 1 involve behaviors absent from her routine. After meeting 3, she surpassed her professional goal: beyond calling two colleagues working on the same subject as him, he also signed up for a conference on the topic. Of the eight goals, the participant failed to achieve only one: talking to her husband about leisure. In meeting 6, emotional, she reported feeling unable to do anything regarding her husband. With the collaboration of the group, she kept working in the marital area by means of a goal she felt she could accomplish: reflecting on her relationship daily for $10 \mathrm{~min}$. In comparing the expectations to the final evaluation, it can be concluded that by using the matrix and group work, the participant achieved her objective of improving organization and emotional management.

Table 5 reveals that participant 2 accomplished all his objectives. The only exception was exceeding his daily coffee intake limit, but that was a goal from the second meeting he kept throughout the intervention "in solidarity" with participant 3 , who originally proposed it. In the life areas of health, profession, and marital relationship, he exceed his goals: he implemented four dietary changes, which resulted in the loss of $4 \mathrm{~kg} 1$ month after the intervention started; listed accomplishing the professional possibilities twice; interacted more calmly with coworkers; and did four activities with his wife, though he had planned only one. When comparing expectations to the final assessment, he achieved his objectives: he discussed retired life, identified new work possibilities, 
Table 2 Qualitative and quantitative evaluations of meeting satisfaction

\begin{tabular}{|c|c|c|c|c|c|}
\hline & \multicolumn{2}{|l|}{ Positive aspects } & \multicolumn{2}{|l|}{ Negative aspects } & \multirow[t]{2}{*}{ Average satisfaction } \\
\hline & Category & $n$ & Category & $n$ & \\
\hline \multirow[t]{4}{*}{ Facilitator } & Assertiveness & 13 & Direction & 4 & \multirow[t]{4}{*}{9.2} \\
\hline & Flexibility & 13 & Clarity & 2 & \\
\hline & Attention to the present & 8 & Time & 2 & \\
\hline & Satisfactory & 3 & & & \\
\hline \multirow[t]{4}{*}{ Content and procedures } & Productive & 8 & Instruction & 4 & \multirow[t]{4}{*}{9} \\
\hline & Clarity & 6 & Time & 4 & \\
\hline & Satisfactory & 3 & Social interaction & 1 & \\
\hline & Tailored & 2 & & & \\
\hline \multirow[t]{3}{*}{ Material } & Satisfactory & 10 & Material & 5 & \multirow[t]{3}{*}{9} \\
\hline & Didactic & 7 & Integrity & 2 & \\
\hline & Responsive & 2 & & & \\
\hline \multirow[t]{3}{*}{ General } & Satisfactory & 8 & Social insertion & 3 & \multirow[t]{3}{*}{9.2} \\
\hline & Personal benefit & 5 & Procedures & 3 & \\
\hline & Social interaction & 4 & Personal matters & 3 & \\
\hline
\end{tabular}

and began developing a business plan. Beyond this, he strengthened his belief in the importance of retirement preparation and learned to plan more achievable goals.

Table 6 shows participant 3 as having accomplished seven goals. Working in the friendship life area, he proposed three goals and achieved two. Comparing expectations to final assessment, it can be concluded that the intervention effects met his demands: the participant identified life areas of interest and chose an activity to dedicate himself to in retirement, a suggestion from participant 2. Additionally, he applied himself to his social life as much with intervention colleagues as friends, the area of greatest interest.

\section{Discussion}

The study described in this research was undertaken with the objective of examining the social validity of a retirement education intervention based on CBS. The intervention presented socially relevant goals by stimulating participants to choose personally interesting tasks and allowing the adaptation of the intervention itself in accordance with their preferences and values. The intervention goals took previous skills into account and promoted new ones relevant to performance in different contexts.

The ability to individualize the activity while collaborating with coworkers meant that the intervention was able to attend to the categories proposed by Lane and Beebe-Frankenberger (2004), encompassing the participants' already existing skills; adapting the intervention to personal preferences, values, and goals; and promoting skills relevant in differing situations. From the point of view of CBS, this result is based on the principle that the unit of analysis is the act-in-context: the intervention attributes to the individual or group, who possesses knowledge of the respective current and historical contexts, the role of establishing which values and goals are relevant, as well as selecting values and goals as a function of the work to be done (Hayes, Strosahl, \& Wilson, 2012).

The procedures were mostly well-received, with emphasis on the role of the facilitator. In the proportion of comments on the facilitator's performance, almost $40 \%$ of the total is consistent with evidence from other intervention implementations (Berkel, Mauricio, Schoenfelder, \& Sandler, 2011; Santos \& Murta, 2015), which indicate the relevance of facilitator behavior on the intervention's outcome. The literature shows that this is an important therapeutic factor (Budd \& Hughes, 2009) and could enhance the quality of mental health services (Laska, Gurman, \& Wampold, 2014). Content that promotes significant personal reflection and well-organized and diversified material have also been shown to be important.

The ACT Matrix was the heart of the intervention. Working the matrix was the main procedure; it shaped identification of goals and proposal of tasks. It deserves special attention because it was used in almost every meeting, and participants adhered with no reservations and worked collaboratively according to each step of the matrix. Its integration with the other procedures is compatible with the instrument's foundations: it was based on the ACT intervention model, which promotes acting according to values, and on the philosophical premise of the human being as a unitary organism, a CBS principle that behaviors, emotions, and physical sensations are on 
Table 3 Type and frequency of activities during the first week

\begin{tabular}{|c|c|c|c|c|c|}
\hline Participant 1 & $F$ & Participant 2 & $F$ & Participant 3 & $r$ \\
\hline \multicolumn{5}{|l|}{ Health } & \\
\hline Physical therapy & 5 & Exercise & 6 & \multirow{4}{*}{$\begin{array}{l}\text { Exercise } \\
\text { Physical therapy }\end{array}$} & \\
\hline Exercise & 6 & Medications & 7 & & \\
\hline Meditation & 6 & & & & \\
\hline Healthy eating & 1 & & & & \\
\hline \multicolumn{5}{|l|}{ Career } & \\
\hline Yoga lessons & 2 & Regular activities & 6 & Regular activities & 5 \\
\hline Yoga studies & 3 & & & & \\
\hline Mantras course & 1 & & & & \\
\hline \multicolumn{5}{|l|}{ Leisure } & \\
\hline Breakfast in the bakery & 1 & Radio in the car & 2 & TV & \\
\hline Reading & 4 & Conversation with son & 1 & Shopping & 2 \\
\hline Music & 1 & Bike ride with son & 1 & Lunch & \\
\hline Swimming pool & 2 & Supermarket & 1 & Dinner & \\
\hline Sauna & 1 & TV & 1 & \multirow[t]{8}{*}{ Travel } & \\
\hline Newspaper & 2 & Visit to relatives & 1 & & \\
\hline Family afternoon & 1 & Son's basketball match & 1 & & \\
\hline TV & 2 & & & & \\
\hline Gongo & 1 & & & & \\
\hline Cinema & 1 & & & & \\
\hline Lunch with relatives & 1 & & & & \\
\hline Gardening & 1 & & & & \\
\hline \multicolumn{5}{|l|}{ Friendship } & \\
\hline N/A & & N/A & & - & \\
\hline \multicolumn{5}{|l|}{ Close relationships } & \\
\hline Breakfast & 1 & Dialog during meals & 5 & \multirow[t]{6}{*}{ N/A } & \\
\hline Lunch (2) & 2 & Son's basketball match & 1 & & \\
\hline Exercise & 1 & Organizing living room & 1 & & \\
\hline Shopping & 1 & Visit to relatives & 1 & & \\
\hline Afternoon with daughters & 1 & & & & \\
\hline Dialog during meals & 1 & & & & \\
\hline
\end{tabular}

$F$ is frequency measured in days

the same level and influence each other-thus, intervening in one of these elements can have repercussions in the others.

As for the procedures in general, however, operational adjustments are still needed. Examples include improving recruitment, fitting the content to the workload, and using more dynamic intervention methods. It is also necessary to improve the instruction and adjust the content to the available time. In part, the instruction can be improved via dynamic methods, such as experiential exercises as well as the adjusting of the material, inserting summaries and page numbers. However, the quality of instruction also depends on the available time. For example, the lack of sufficient time did not permit complete exposition of the material and limited discussion opportunities among the participants.

The intervention advanced socially important effects by means of sequential behavioral changes in line with the life domain being worked and compatible with the participants' expectations. The results demonstrate the viability of instigating new behaviors based on significant values through retirement education. In the three groups, the sharing of values, aversive internal events, and dysfunctional behaviors occurred in a natural way and increased over the course of the intervention. While establishing goals, the participants collaborated, offering and soliciting suggesting to their peers. In general, achieving personally meaningful results reinforces the 
Table 4 Expectations, goals, and evaluations of participant 1

\begin{tabular}{|c|c|c|c|c|c|}
\hline \multicolumn{6}{|l|}{ Expectations } \\
\hline Question & \multicolumn{5}{|c|}{ Participant's answer } \\
\hline $\begin{array}{l}\text { Why did I seek out } \\
\text { this activity? }\end{array}$ & \multicolumn{5}{|c|}{$\begin{array}{l}\text { I need more focus, more reality, to be more } \\
\text { "grounded," and to get better organized regarding } \\
\text { time; opportunities to talk, work, organize, and put } \\
\text { into action what I want to do from now on; to talk } \\
\text { and deal with the fear of the new and the unknown } \\
\text { path. }\end{array}$} \\
\hline $\begin{array}{l}\text { What do I expect to } \\
\text { achieve by the end } \\
\text { of the activity? }\end{array}$ & \multicolumn{5}{|c|}{$\begin{array}{l}\text { To have put more order in and higher priority on } \\
\text { what I want to do; to have guidance for how am I } \\
\text { going to do what I want to do; to have gained some } \\
\text { "capacity" or tools to deal with my insecurity and fear } \\
\text { - so these do not hinder me. }\end{array}$} \\
\hline \multicolumn{6}{|l|}{ Goals } \\
\hline \multirow[t]{2}{*}{ Activity } & \multicolumn{5}{|c|}{ Life domain and meeting number } \\
\hline & $\begin{array}{l}\text { Health } \\
\text { meeting } \\
2\end{array}$ & $\begin{array}{l}\text { Career } \\
\text { meeting } \\
3\end{array}$ & $\begin{array}{l}\text { Leisure } \\
\text { meeting } \\
4\end{array}$ & $\begin{array}{l}\text { Career } \\
\text { meeting } \\
5\end{array}$ & $\begin{array}{l}\text { Couples } \\
\text { meeting } \\
6\end{array}$ \\
\hline $\begin{array}{l}\text { To meditate } 5 \text { days a } \\
\text { week, at } 5 \text { am }\end{array}$ & Yes & $<1$ & Yes & Yes & Yes \\
\hline $\begin{array}{l}\text { Call coworkers, } \\
\text { physician, and } \\
\text { psychologist }\end{array}$ & \multicolumn{5}{|c|}{$>^{2}$} \\
\hline $\begin{array}{l}\text { Talk to husband } \\
\text { about leisure } \\
\text { together }\end{array}$ & \multicolumn{5}{|c|}{ No } \\
\hline $\begin{array}{l}\text { Read an item from } \\
\text { the class }\end{array}$ & \multicolumn{5}{|c|}{ Yes } \\
\hline $\begin{array}{l}\text { Quit a few } \\
\text { professional projects }\end{array}$ & \multicolumn{5}{|c|}{ Yes } \\
\hline \multicolumn{6}{|l|}{ Final evaluation } \\
\hline Question & \multicolumn{5}{|c|}{ Participant's answer } \\
\hline $\begin{array}{l}\text { When I compare my } \\
\text { expectations to my } \\
\text { results, I think that: }\end{array}$ & \multicolumn{5}{|c|}{$\begin{array}{l}\text { I really saw the need to prioritize and I started the } \\
\text { process of prioritizing between the lessons I took and } \\
\text { in the areas where I can act. I learned a tool - [the } \\
\text { ACT] Matrix - which will help me to walk through } \\
\text { this process. I learned the importance of the group } \\
\text { (any kind of group) in my personal project. Personal } \\
\text { project does not mean isolation nor that will it } \\
\text { happen if I isolate myself. }\end{array}$} \\
\hline
\end{tabular}

Meditated 4 days a week

${ }^{2}$ Also registered at a conference of interest

potential of interventions for retirement education (Leandro-França et al., 2016). The participants had quite diverse goals and, at times, they addressed distinct areas of life in the same meeting, but the focus on values presented a common thread, promoting group work and permitting the development of distinct interests. However, the absence of a follow-up did not permit evaluation of the maintenance of the new behaviors.

In accordance with the strategy that guided the intervention development, the high acceptability of effects is based on two principles of functional contextualism: prediction and influence of behavior. Both are distinct objectives, so an effective intervention must meet both. The analysis should be deep enough to boost the intervention's effectiveness, leading to the optimization of time and targeting the intervention's activities.
Table 5 Expectations, goals, and evaluations of participant 2

\begin{tabular}{ll}
\hline Expectations & \\
Question & Participant's answer \\
Why did I & I have been in public service for 46 years; I never \\
seek out this & acted without being employed [by a company or \\
activity? & government]; it's time to think about what to do in \\
& the upcoming years. I do not want to waste what I \\
& learned. I know how to help people and I want to \\
& continue doing so.
\end{tabular}

What do I A plan for activities to be performed as a selfexpect to employed individual. Some possibilities for work. To achieve by learn more about life after retirement.

the end of

the activity?

\section{Goals}

Activity

Life domain and meeting number

Activity

Eat up to 3

slices of

wholegrain

bread per

day

\section{Drink at}

most 2 cups

of coffee per

day

List five

options for

future

professional

activities

Do 2 leisure

activities

with wife

Structure

and write

down

business

plans

Pay attention

to son's

bedtime

Final evaluation

\section{Question Participant's reply}

When I The results exceeded my expectations greatly. I've compare my learned with my group of colleagues how to think, expectations plan, and share ideas about the future. I have to to my have challenging but attainable goals. The meetings results, I helped to highlight the need to plan for the future think that: based on social and psychological factors (the predictors) which interfere in people's adjustment, in my adjustment, when I retire.

\section{${ }^{1}$ Changed his goal to up to 2 slices of bread per day}

${ }^{2}$ Exceeded the goal limit

${ }^{3}$ Listed 10 options

${ }^{4}$ Happy hour, 2 movies at the theater, getting groceries, preparing lunch, riding a bicycle

${ }^{5}$ Reported that other changes started after the beginning of the intervention: eliminated after-work snack; reduced eating at night; lost 4 kg; at work, acted with less criticism and more calmly 
Table 6 Expectations, goals, and evaluations of participant 3

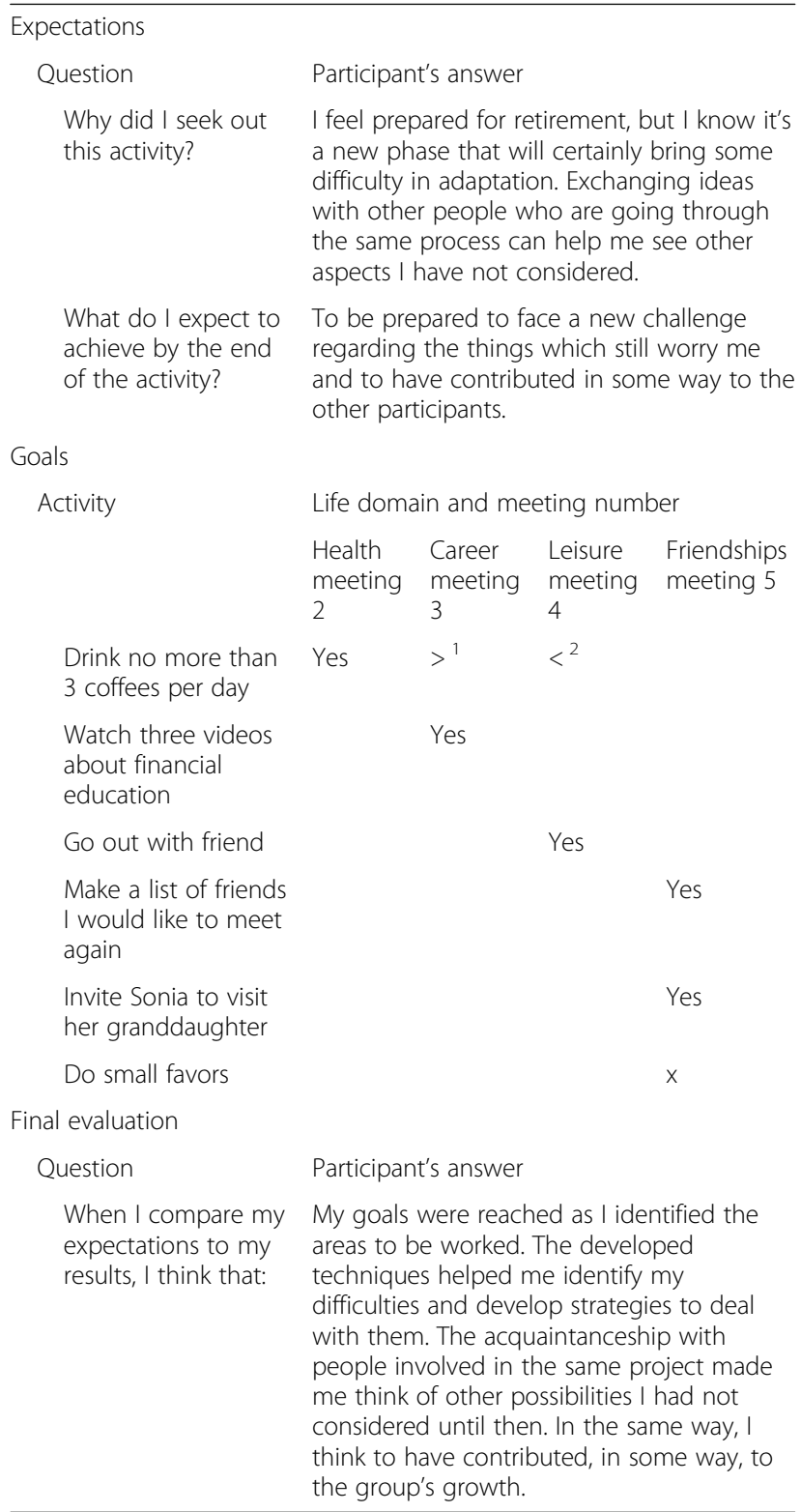

${ }^{1}$ Changed the goal to no more than 2 coffees per day

${ }^{2}$ Exceeded the goal limit

${ }^{3}$ Participant 3 missed meeting 6; thus, she had no new goals. However, she emailed her task record for the week before

The intervention evaluated in this study also presents two important limitations. The first is the independence of the evaluator: preventive programs whose evaluations are done by their own creators tend to report more favorable results (Eisner, 2009). Due to the study conditions, however, external evaluation was infeasible. The second important limitation is the absence of a followup evaluation to verify the maintenance of social validity of the effects. Although the effectiveness evaluation exceeded the goals of these pilot studies, preventive interventions should conduct at least one long-term follow-up to evaluate the maintenance of its results (Gottfredson et al., 2015).

Based on the conclusions from the analysis of the three groups, it is possible to outline some next steps for research on the development of interventions for retirement preparation. From a public health perspective, the participant selection step should be done in a systematic manner by the researchers, minimizing sample bias and boosting external validity of the data. To foster implementation quality, in turn permitting a reliable measurement of the effects, it is important to work in closed groups. Finally, evaluating moderators and mediators in terms of, for example psychological flexibility, in efficacy studies can clarify the contextual aspects that interfere with the intervention's functionality.

Solid and socially relevant knowledge production can boost scientific and social development. CBS brings a strategy for organizing and making sense of available knowledge, which should improve the quality of newly produced knowledge. Social validity complements this process, bestowing more meaning on the research. For many immersed in the academic world, the discrepancy between the effort involved in the production of knowledge and its low social impact is frustrating. Evaluating social validity may reveal this lack of impact, presaging receptiveness to a new intervention. In principle, this would permit modifications which foster the dissemination of the intervention, completing the cycle of research into prevention and the promotion of mental health as well as promoting quality of life.

\section{Conclusion}

This study makes two principle contributions. The first is the use of CBS as a guide for developing interventions (Hayes et al., 2013). The construction of the intervention starting from philosophical premises, theories, and methods compatible with CBS shows the integration of suppositions with application. Contextual functionalism principles inspired goal planning, instrument selection, and behavior change activities. The promotion of valuesbased behaviors, leading to new protective behaviors, shows the emphasis of the intervention on functional and manipulable processes. The simplicity of the intervention, based on a manageable applied instrument with individualized goals, should facilitate its implementation and dissemination. The construction of a preventive group intervention with flexible objectives is compatible with the practicality demanded by public health care. The weekly monitoring of goals revealed the elevated commitment of the participants, a sign of the intervention's acceptability. Also, the promotion of new behaviors in different areas of life demonstrates that the intervention has cross-sectional reach. Finally, these exploratory studies reinforce the expectation that the 
strategic argument proposed by CBS is a call to promising action (Hayes, Strosahl, \& Wilson, 2012).

Within the intervention development, the use of CBS to develop a retirement education intervention stands out for this intervention's preventive nature. Looking at the 144 clinical studies based on ACT published between 1986 and 2015, only seven mentioned prevention of negative outcomes or promotion of mental health in their titles (Association for Contextual Behavioral Science, 2016). Furthermore, there are no records of clinical studies based on ACT nor of publications related to CBS that address the adjustment to retirement (Association for Contextual Behavioral Science, 2016). Beyond this, the measurement of results via a daily record of behavior and not by interviews or scales is unique in retirement preparation interventions (Leandro-França et al., 2016). Therefore, the science of prevention and the practice of preparation for retirement can also benefit from the structure and contextual thinking of CBS.

The second contribution is the evaluation of the intervention's social validity. Although social validity might foster the adoption and dissemination of an intervention, this is uncommon in the context of retirement. None of the 11 retirement preparation studies reviewed by LeandroFrança et al. (2016) addressed social validity. All in all, only five evaluated the perceived satisfaction and only three undertook a needs survey prior to the trial. On the other hand, the relevance of social validity is clear: the effectiveness of an intervention is not enough to assure its acceptance by users-equally effective interventions are not necessarily equally accepted (Carter, 2010). While social validity is not sufficient to guarantee results, it is an important prerequisite for intervention implementation and dissemination in the real world.

In conclusion, according to the participants' evaluations, the intervention provided socially valid goals, socially acceptable procedures, and socially important effects. However, some improvements are still needed, such as the use of more dynamic methods, better formatted printed material, and increased fidelity between the implementation of the content and the prescribed activities. The positive results indicate that contextual behavioral science may bolster the development of interventions based on components with evidence for social validity. The re-evaluation of the intervention via a clinical trial study should offer more robust evidence for its effectiveness. It is hoped that by increasing the availability of theory-based interventions in this area, the present study will promote valid strategies to facilitate better adjustment to retirement.

\section{Abbreviations}

ACT: Acceptance and commitment therapy; CBS: Contextual behavioral science; SGP: Survey of Guiding Principles; TIDieR: Template for Intervention Description and Replication Checklist and Guide; VLQ: Valued Living Questionnaire
Acknowledgements

Not applicable.

Authors' contributions

LMB was responsible for data collection, data analysis, and writing. SGM was responsible for research design and writing review. Both authors read and approved the final manuscript.

\section{Funding}

Not applicable.

Availability of data and materials

Data are available from the first author (email: leopfa@gmail.com).

\section{Ethics approval and consent to participate}

The study was approved by the Committee for Ethics in Human and Social Sciences of the University of Brasilia. All participants were properly informed of their rights. Informed consent forms were signed by those who agreed to participate.

\section{Consent for publication}

Not applicable.

\section{Competing interests}

The authors declare that they have no competing interests.

Received: 24 July 2019 Accepted: 22 November 2019

Published online: 23 December 2019

\section{References}

Association for Contextual Behavioral Science (2016). ACBS. Association for Contextual Behavioral Science Retrieved from https://contextualscience.org/ publications.

Baer, D. M., \& Wolf, M. M. (1987). Some still-current dimensions of applied behavior analysis. Journal of Applied Behavior Analysis, 20(4), 313-327. https:// doi.org/10.1901/jaba.1987.20-313.

Barbosa, L. M., Monteiro, B., \& Murta, S. G. (2016). Retirement adjustment predictors: A systematic review. Work, Aging and Retirement. https://doi.org/ 10.1093/workar/waw008.

Barbosa, L. M., \& Murta, S. G. (2014). Terapia de aceitação e compromisso: História, fundamentos, modelo e evidências. Revista Brasileira de Terapia Comportamental e Cognitiva, 16(3), 34-49. https://doi.org/10.31505/rbtcc. v16i3.711.

Bartholomew, L. K., \& Mullen, P. D. (2011). Five roles for using theory and evidence in the design and testing of behavior change interventions. Journal of Public Health Dentistry, 71. https://doi.org/10.1111/j.1752-7325.2011.00223.x.

Berkel, C., Mauricio, A. M., Schoenfelder, E., \& Sandler, I. N. (2011). Putting the pieces together: An integrated model of program implementation. Prevention Science, 12, 23-33. https://doi.org/10.1007/s11121-010-0186-1.

Biglan, A. \& Hayes, S. C. (1996). Should the behavioral sciences become more pragmatic? The group for functional contextualism in research on human behavior. Applied and Preventive Psychology, 5, 47-57.

Boehs, S. T. M., Medina, P. F., Bardagi, M. P., Luna, I. N., \& Silva, N. (2017). Revisão da literatura latino-americana sobre aposentadoria e trabalho: Perspectivas psicológicas. Revista Psicologia: Organizações e Trabalho, 17(1), 54-61. https:// doi.org/10.17652/rpot/2017.1.11598.

Bonsang, E., \& Klein, T. J. (2012). Retirement and subjective well-being. Journal of Economic Behavior \& Organization, 83(3), 311-329. https://doi.org/10.1016/j. jebo.2012.06.002.

Braun, V., \& Clarke, V. (2006). Using thematic analysis in psychology. Qualitative Research in Psychology, 3, 77-101. https://doi.org/10.1191/ 1478088706qp0630a.

Budd, R., \& Hughes, I. (2009). The dodo bird veredict - controversial, inevitable and important: A commentary on 30 years of meta-analyses. Clinical Psychology \& Psychotherapy, 16, 510-522. https://doi.org/10.1002/cpp

Carter, S. L. (2010). The social validity manual. San Diego: Academic.

Ciarrochi, J., \& Bailey, A. (2008). A CBT-Practitioner's guide to ACT: How to bridge the gap between cognitive behavioral therapy and acceptance and commitment therapy. Oakland: New Harbinger Publications, Inc.

Durlak, J. A., \& DuPre, E. P. (2008). Implementation matters: A review of research on the influence of implementation on program outcomes and the factors 
affecting implementation. American Journal of Community Psychology, 41, 327-350. https://doi.org/10.1007/s10464-008-9165-0.

Eisner, M. (2009). No effects in independent prevention trials: Can we reject the cynical view? Journal of Experimental Criminology, 5(2), 163-183. https://doi. org/10.1007/s11292-009-9071-y.

Fawcett, S. B. (1991). Social validity: A note on methodology. Journal of Applied Behavior Analysis, 24(2), 235-239. https://doi.org/10.1901/jaba.1991.24-235.

Gottfredson, D. C., Cook, T. D., Gardner, F. E. M., Gorman-Smith, D., Howe, G. W. Sandler, I. N., \& Zafft, K. M. (2015). Standards of evidence for efficacy, effectiveness, and scale-up research in prevention science: Next generation. Prevention Science, 16, 893-926. https://doi.org/10.1007/s11121-015-0555-X.

Hayes, S. C., Barnes-Holmes, D., \& Roche, B. (2001). Relational frame theory: A postskinnerian account of human language and cognition. New York: Kluwer Academic/Plenum Publishers.

Hayes, S. C., Barnes-Holmes, D., \& Wilson, K. G. (2012). Contextual behavioral science: Creating a science more adequate to the challenge of human condition. Journal of Contextual Behavioral Science. https://doi.org/10.1016/j. jcbs.2012.09.004.

Hayes, S. C., \& Brownstein, A. J. (1986). Mentalism, behavior-behavior relations, and a behavior-analytic view of the purposes of science. The Behavior Analyst, 9, 175-190.

Hayes, S. C., Hayes, L. J., \& Reese, H. W. (1988). Finding the philosophical core: A review of Stephen C. Pepper's world hypotheses: A study in evidence. Journal of the Experimental Analysis of Behavior, 50(1), 97-111.

Hayes, S. C., Long, D. M., Levin, M. E., \& Follette, W. C. (2013). Treatment development: Can we find a better way? Clinical Psychology Review, 33(7), 870-882. https://doi.org/10.1016/j.cpr.2012.09.009.

Hayes, S. C., Luoma, J. B., Bond, F. W., Masuda, A., \& Lillis, J. (2006). Acceptance and commitment therapy: Model, processes and outcomes. Behaviour Research and Therapy, 44(1), 1-25. https://doi.org/10.1016/j.brat.2005.06.006.

Hayes, S. C., Strosahl, K. D., \& Wilson, K. G. (2012). Acceptance and commitment therapy: The process and practice of mindful change, ( $2^{\mathrm{a}} \mathrm{ed} .$, ). New York: Guilford Press.

Herbert, J. D., Gaudiano, B. A., \& Forman, E. M. (2013). The importance of theory in cognitive behavior therapy: A perspective of contextual behavioral science. Behavior Therapy. https://doi.org/10.1016/j.beth.2013.03.001

Hoffmann, et al. (2014). Better reporting of interventions: Template for intervention description and replication (TIDieR) checklist and guide. BMJ 348,1687

Hurtado, M. D., \& Topa, G. (2019). Quality of life and health: Influence of preparation for retirement behaviors through the serial mediation of losses and gains. International Journal of Environmental Research and Public Health, 16(1539). https://doi.org/10.3390/ijerph16091539.

Kämpfen, F., \& Maurer, J. (2016). Time to burn (calories)? The impact of retirement on physical activity among mature Americans. Journal of Health Economics, 45, 91-102. https://doi.org/10.1016/j.jhealeco.2015.12.001.

Kanter, J. W., Busch, A. M., \& Rusch, L. C. (2009). Behavioral activation: Distinctive features. New York: Routledge.

Lane, K. L., \& Beebe-Frankenberger, M. (2004). School-based interventions: The tools you need to succeed (pp. 85-127). Boston: Pearson.

Laska, K. M., Gurman, A. S., \& Wampold, B. E. (2014). Expanding the lens of evidence-based practice in psychotherapy: A common factors perspective. Psychotherapy, 51(4), 467-481. https://doi.org/10.1037/a0034332.

Leandro-França, C., Murta, S. G., Hershey, D. A., \& Barbosa, L. M. (2016). Evaluation of retirement planning programs: A qualitative analysis of methodologies and efficacy. Educational Gerontology, 42(7), 497-512. https://doi.org/10.1080/ 03601277.2016 .1156380

Lewin, K. (1951). Problems of research in social psychology. In D. Cartwright (Ed.), Field theory in social science: Selected theoretical papers, (pp. 155-169). New York: Harper \& Row.

Muñoz, R. F., Mrazek, P. J., \& Haggerty, R. J. (1996). Institute of Medicine report on prevention of mental disorders. American Psychologist, 51(11), 1116-1122.

Murta, S. G., Moura, S. A., França, C. L., Pedralho, M., Seidl, J., Lira, N. d. P. M., .. de Gunther, I., A. (2014). Preparação para a aposentadoria: Implementação e avaliação do programa Viva Mais! Revista Psicologia: Reflexão E Crítica, 27(1), 1-9. https://doi.org/10.1590/S0102-79722014000100001.

Murta, S. G., \& Santos, K. B. (2015). Desenvolvimento de programas preventivos e de promoção em saúde mental. In S. G. Murta, C. Leandro-França, K. B. dos Santos, \& L. Polejack (Eds.), Prevenção e promoção em saúde mental: Fundamentos, planejamento e estratégias de intervenção, (pp. 168-191). Novo Hamburgo: Sinopsys.
Nimrod, G., Janke, M. C., \& Kleiber, D. A. (2008). Retirement, activity, and subjective well-being in Israel and the Unites States. World Leisure, 1, 18-32. https://doi.org/10.1080/04419057.2008.9674524.

Pazzim, T. A., \& Marin, A. H. (2017). Retirement preparation program: Evaluation of results. Psicologia: Reflexão e Crítica, 30(24). https://doi.org/10.1186/s41155017-0079-3.

Pepper, S. C. (1942). World hypotheses: A study in evidence. Berkeley: University of California.

Polk, K., \& Schoendorff, B. (2014). The ACT Matrix: A new approach to building psychological flexibility across settings and populations. Oakland: Context Press.

Rohrbach, L. A. (2014). Design of prevention interventions. In Z. Sloboda, \& H. Petras (Eds.), Defining prevention science, (pp. 275-291). New York: Springer.

Santos, K. B., \& Murta, S. G. (2015). A implementação de programas de prevenção e promoção no âmbito da saúde mental. In S. G. Murta, C. Leandro-França, K. B. dos Santos, \& L. Polejak (Eds.), Prevenção e promoção em saúde mental: Fundamentos, planejamento e estratégias de intervenção, (pp. 192-211). Novo Hamburgo: Sinopsys.

Szinovacz, M. E., \& Davey, A. (2001). Retirement effects on parent-adult child contacts. The Gerontologist, 41(2), 191. https://doi.org/10.1093/geront/41.2.191.

Szinovacz, M. E., \& Davey, A. (2005). Retirement and marital decision making: Effects on retirement satisfaction. Journal of Marriage and Family, 67(2), 387398. https://doi.org/10.1111/j.0022-2445.2005.00123.x.

van der Heide, I., van Rijn, R. M., Robroek, S. J. W., Burdorf, A., \& Proper, K. I. (2013). Is retirement good for your health? A systematic review of longitudinal studies. BMC Public Health, 13, 1180. https:/doi.org/10.1186/1471-2458-13-1180.

Vilardaga, R., Hayes, S. C., Levin, M. E., \& Muto, T. (2009). Creating a strategy for progress: A contextual behavioral science approach. The Behavior Analyst, 32(1), 105-133. https://doi.org/10.1007/bf03392178.

Wang, M., Henkens, K., \& van Solinge, H. (2011). Retirement adjustment: A review of theoretical and empirical advancements. The American Psychologist, 66(3), 204-213. https://doi.org/10.1037/a0022414.

Wilson, K. G., Sandoz, E. K., Kitchens, J., \& Roberts, M. (2010). The valued living questionnaire: Defining and measuring valued action within a behavioral framework. The Psychological Record, 60, 249-272. https://doi.org/10.1007/ BF03395706.

Wolf, M. M. (1978). Social validity: The group for subjective measurement or how applied behavior analysis is finding its heart. Journal of Applied Behavior Analysis, 11(2), 203-214. https://doi.org/10.1901/jaba.1978.11-203.

\section{Publisher's Note}

Springer Nature remains neutral with regard to jurisdictional claims in published maps and institutional affiliations.

\section{Submit your manuscript to a SpringerOpen ${ }^{\circ}$ journal and benefit from:}

- Convenient online submission

- Rigorous peer review

- Open access: articles freely available online

- High visibility within the field

- Retaining the copyright to your article

Submit your next manuscript at $\boldsymbol{\nabla}$ springeropen.com 